\title{
Fatal Occupational Injuries in the U.S. Commercial Fishing Industry: Risk Factors and Recommendations
}

\section{East Coast Region}

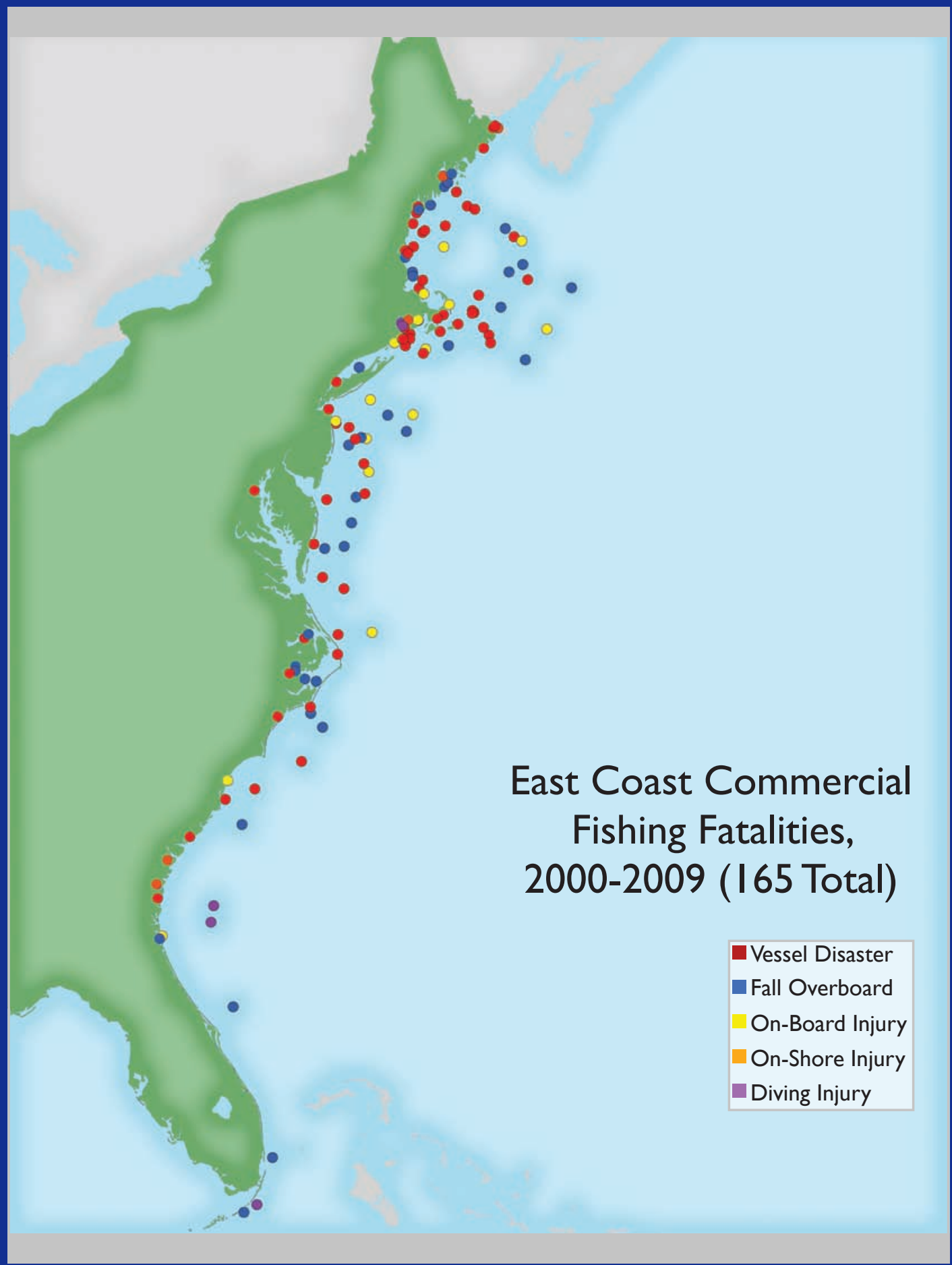




\section{About This Report}

The National Institute for Occupational Sa fety and Health (NIOSH) is the federal govemment a gency responsible for conducting research and making recommendations for the prevention of work-related injury and illness. NIOSH recently completed an in-depth study of commercial fishing fatalities in the United States during $2000-2009$. The purpose of the study was to identify the most hazardous fisheries around the country and to describe the unique safety issues in each. For this study the US was divided into four fishing regions: Alaska, West Coast, East Coast, and the Gulf of Mexico. This document is one in a set of four reports summarizing fatality data for US fishing regions.

\section{East Coast Commercial Fishing Fatalities by Year and Incident Type (I65 Total) Figure 1}

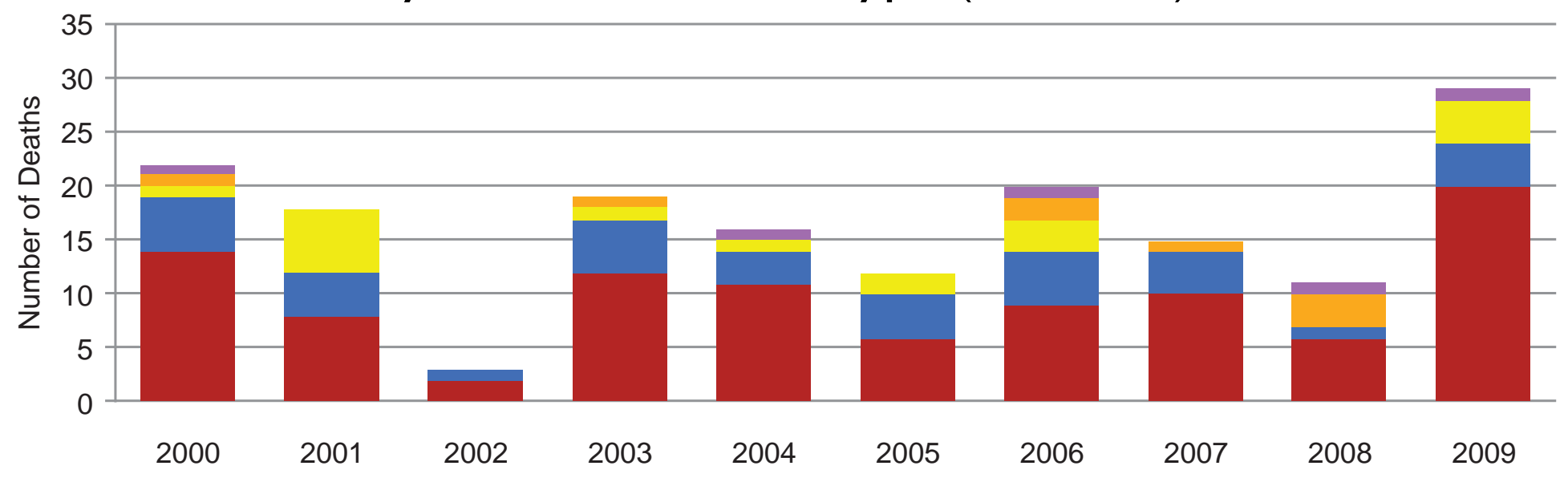

During 2000-2009, 165 commercial fishing deaths occurred off the East Coast of the US, an average of 17 per year (Fig. 1). During 2002, the number of fatalities was unusually low, with only three deaths. No explanation for the single-year decrease has been identified. 2009 was an especially tragic year with 29 fatalities.

About $60 \%$ of the total deaths were caused by drowning following a vessel disaster (e.g. sinking, capsizing, fire, etc) in which the crew was forced to abandon ship (Fig. 2). About one-quarter (22\%) of fatalities were the result of falls overboard. The remaining fatalities were due to traumatic injuries susta ined onboard, on-shore, or while diving.

Fatalities occurred in 24 different fisheries on the East Coast. Eleven fisheries had five or more fatalities, and accounted for $84 \%$ of the total fatalities (Fig. 3). The Scallop fishery experienced the highest number of occupational deaths with 44 fatalities. Vessel disasters caused the most deaths among Scallop fishermen (30, $68 \%$ ). The remaining fatalities were caused by falls overboard, on-board injuries and on-shore injuries.

The multi-species groundfish fishery also suffered a high number of fatalities, with 26 deaths. Vessel disasters caused 19 (73\%) of the fatalities, and 6 $(23 \%)$ were caused by on-board injuries. Four of the on-board fatalities were caused by entanglement in deck winches.

Most of the fatalities in the Northeast Lobster fishery were caused by falls overboard $(11,61 \%)$. About half $(5,45 \%)$ of falls overboard were caused by being pulled or pushed overboard by fishing gear.

While the Scallop fishery claimed the highest number of lives during 2000-2009, the multi-species groundfish fishery carried a higher risk of death, as measured by the fatality rate (Table 1). The fatality rate accounts for the number of workers and exposure time on the water, and provides a way to compare risk using a common denominator.

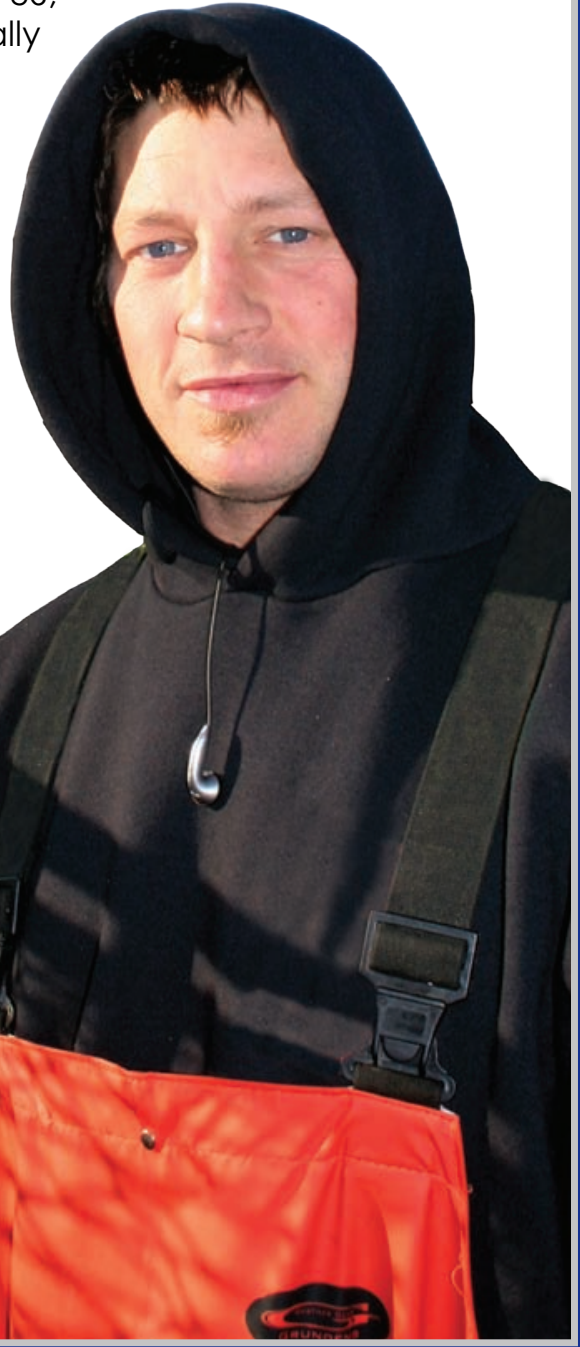


Fatality rates for other fisheries were not able to be calculated due to missing workforce data.

Vessel disasters often result in multiple fatalities. The 98 deaths due to vessel disasters during 2000-2009 took place in 59 separate incidents. Vessel disasters were usually caused by a sequence of events, starting with an initiating event. The most common initiating events were: flooding, vessel instability, being struck by a large wave, and collisions (Fig. 4). In addition, Severe weather conditions contributed to $54 \%$ of vessel disasters. In the scallop fishery, 12 vessel disasters killed 30 fishermen. The two most common initiating events were collisions $(3,25 \%)$ and vessel instability $(3,25 \%)$. Flooding and gearcaught on the bottom initiated two vessel disasters each. In the multi-species groundfish fishery, 12 vessel disasters killed 19 fishermen. Vessel instability was the main initiating event $(5,42 \%)$, followed by flooding $(4,33 \%)$.

Falls overboard accounted for $22 \%$ of all fatalities in the East Coast commercial fishing industry during 2000-2009. Falls overboard were caused most often by losing balance and by entanglement in fishing gear (Fig 5). Factors that contributed to falls overboard were: working alone on deck (53\%), using alcohol or drugs (11\%), and poor weather conditions (8\%). None of the victims of falls overboard were wearing a Personal Flotation Device (PFD).

\section{East Coast Fisheries with Five or More Fatalities During 2000-2009 (I 38 Total)}

Figure 3

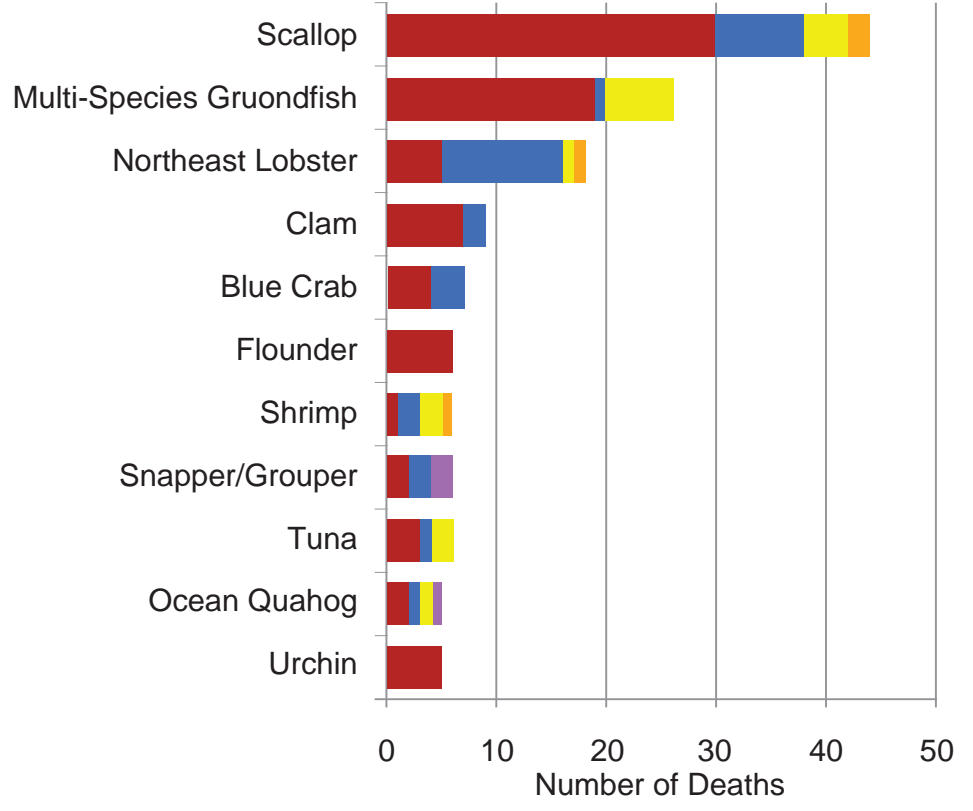

\section{East Coast Commercial Fishing} Fatalities by Incident Type (I 65 Total)

Figure 2

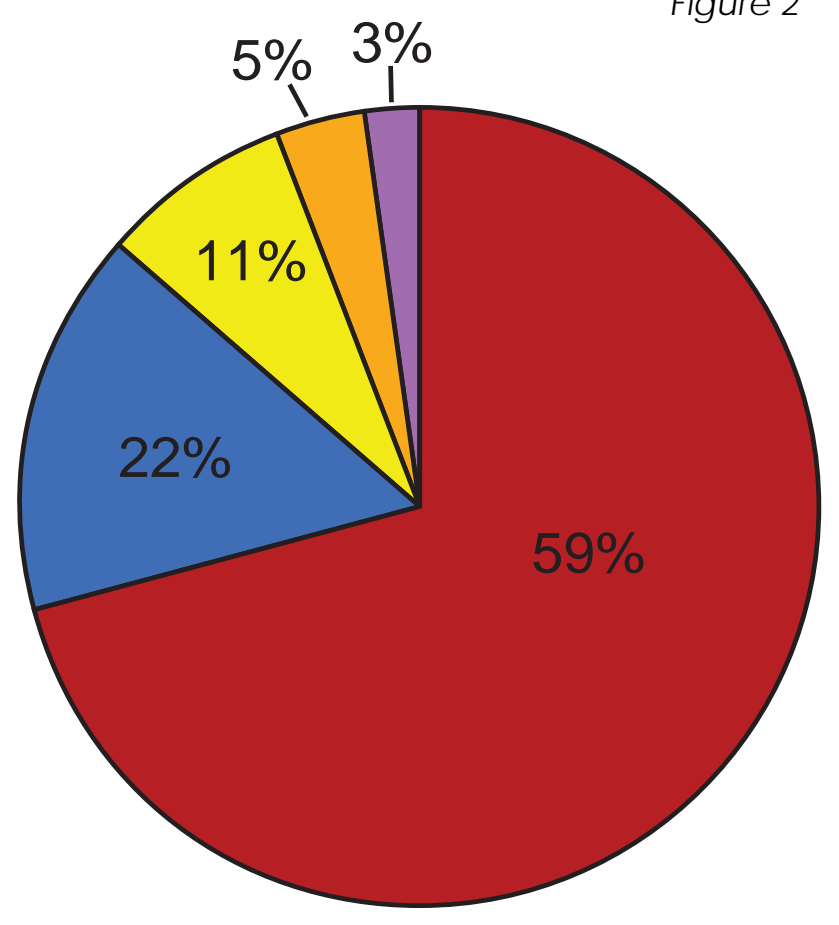

Commercial Fishing Fatality Rates for Full-time Equivalent (FTE) Workers, East Coast, 2000-2009 Table 1

\begin{tabular}{|l|c|c|c|}
\hline \multicolumn{1}{|c|}{ Fishery } & Fatalities & FTEs & $\begin{array}{c}\text { Annual } \\
\text { rate per } \\
\text { 100,000 } \\
\text { FTEs }\end{array}$ \\
\hline $\begin{array}{l}\text { Northeast } \\
\text { Multi-species } \\
\text { Groundfish }\end{array}$ & 26 & 4,340 & 600 \\
\hline $\begin{array}{l}\text { Atlantic } \\
\text { Scallop }\end{array}$ & 44 & 10,384 & 425 \\
\hline $\begin{array}{l}\text { Atlantic } \\
\text { Snapper/ } \\
\text { Grouper }\end{array}$ & 6 & 3,622 & 170 \\
\hline
\end{tabular}

* Rates were calculated by dividing the total number of fatalities for the 10 year period by the total annual FTE.

\section{Data Key}

Vessel Disaster

Fall Overboard

On-Board Injury

On-Shore Injury

Diving Injury

\section{Conclusions}

The multi-species groundfish fishery had an exceptionally high fatality rate during 2000-2009. Most of the fatalities occurred following vessel disasters. The results of this a nalysis showed that the two most frequent initia ting events for vessel disasters in this fishery were vessel instability and flooding. Prevention efforts should focus on preventing those two situations from occurring, as well as continued training and outfitting to better prepare fishermen to survive vessel disasters. Installing e-stops to stop winches when entanglement occurs can also prevent fata lities found in this fishery. 
The scallop fishery had the highest number of deaths during 2000-2009, as well as a high fatality rate. Preventing the hazards leading to collisions, vessel instability, flooding, and snagging gear on the ocean floor is necessary. A previous study on the scallop fleet in Maine reported a distinct pattern of serious injuries and vessels capsizing in the mid-1990s while towing fishing apparatus across the sea bed or while lifting laden fishing apparatus from the water to recover the catch. USCG personnel then engaged the fishermen in town hall meetings to discuss the hazards and potential solutions. This type of an approach could be repeated for the entire Atlantic scallop fleet and an evaluation should be done for its effectiveness.

The Northeast lobster fishery also suffered a high number of occupational deaths. Most of the fatalities were caused by falls overboard, often as a result of gear entanglement or being knocked over by gear. Increasing the wearing of PFDs, preventing gear entanglement, and identifying effective recovery methods after a fall overboard should be priorities in this fishery. Entanglement prevention ideas were identified in a previous study through interviewing lobstermen and include the use of line bins and rope lockers. Calculating workforce estimates for this fleet would also assist in assessing the risk of this fishery.

\section{Initiating Events Contributing to Fatal Vessel Disasters, East Coast, 2000-2009 (59 Disasters with 98 Deaths)Figure 4}

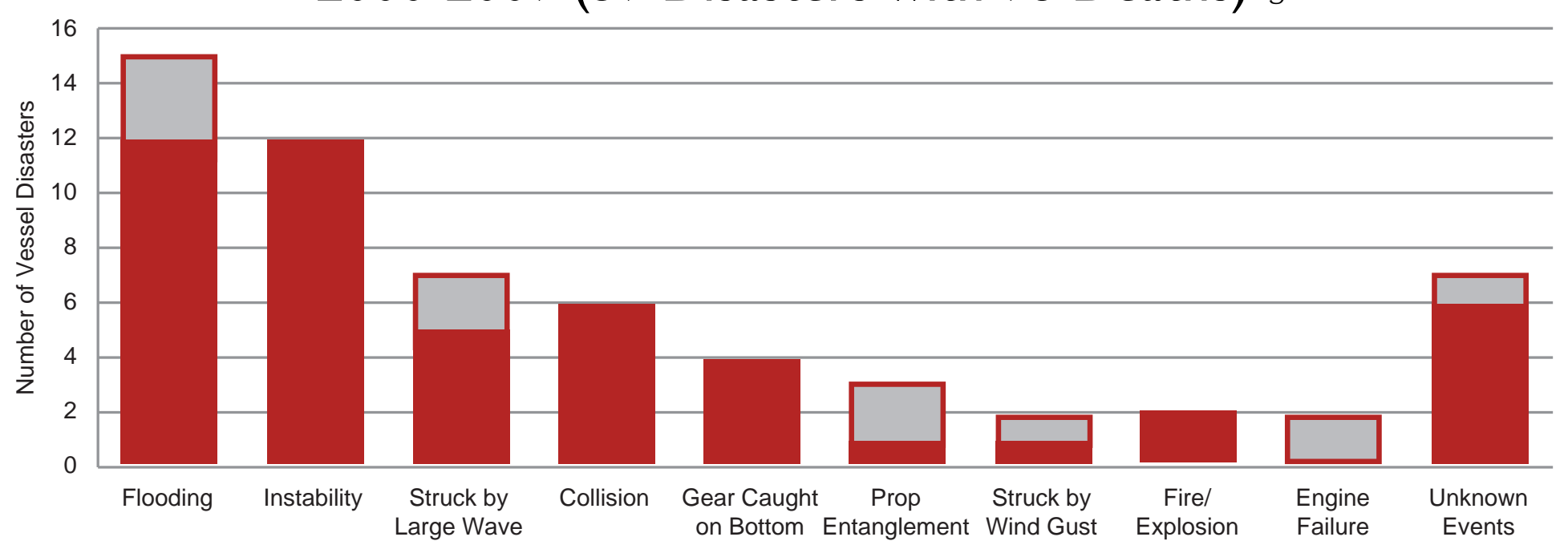

Undecked (skiff) D Decked

\section{Causes of Fatal Falls Overboard, East Coast, 2000-2009 (36 Total) Figure 5}

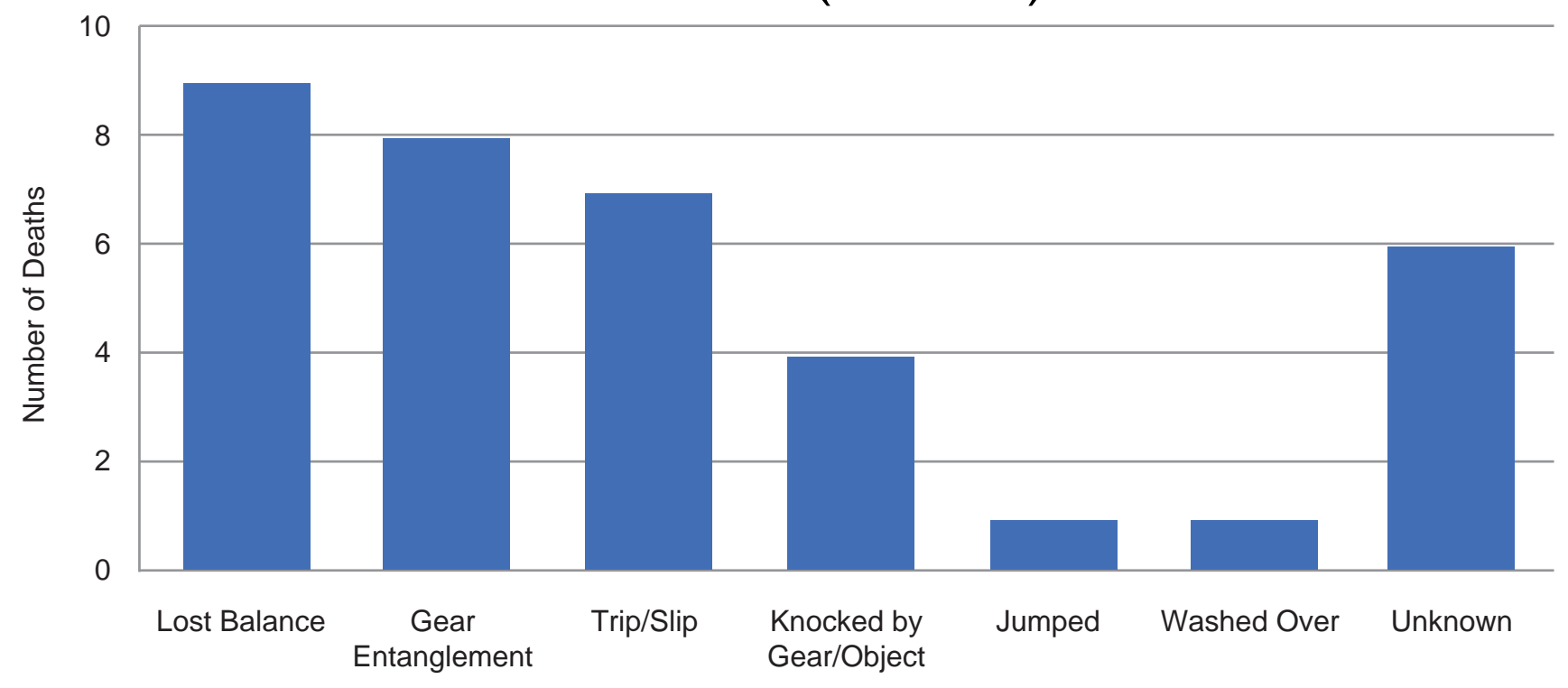




\section{RECOMMENDATIONS}

\section{Vessel Disasters}

Take a marine safety class at least once every 5 years - Safety training for fishermen is available, affordable, and saves lives. All fishermen should learn and know how to use basic lifesaving equipment like immersion suits, life rafts, EPIRBs, and fire extinguishers.

Do monthly drills: Abandon ship, Fooding, Fre - Safety training equips fishermen with survival skills and knowledge. Monthly drills give fishermen an opportunity to practice and re-enforce those skills.

Test immersion suit for leaks - When watertight, immersion suits provide thermal protection and flotation in cold water. If an immersion suit has leaks, it will provide less protection from cold water. Instructions for inflation testing immersion suits are available at www.amsea.org.

Heed weather forecasts and avoid fishing in severe sea conditions - Make the decision to stay in port when the seas are too rough for your vessel to operate in. Keep track of forecasts and seek shelter before the storm arrives or intensifies beyond the safe operating limits of your vessel.

Maintain watertight integrity - Inspect and maintain the hull of your vessel and all through-hull fittings. When seas are rough, ensure that watertight doors and hatches are sealed. Inspect and test high water a la ms regula rly.

\section{Falls Overboard}

Weara PFD on deck - Falls overboard occur without waming or time to prepare. A PFD stowed away onboard will not help float a fisherman who has fallen overboard. Wearing a PFD on deck is the single most important thing a fisherman can do to increase survivability following a fall overboard. There are many new styles of PFDs which have been evaluated by fishermen in real working conditions and are comfortable to work in on deck. Results of the NIOSH PFD study are available at www.cdc.gov/niosh/topics/fishing.

Utilize a man overboard alam system - Man overboard alarms are devices which alert others instantly to a fall overboard emergency, even if the fall was not witnessed. Systems vary in features and cost, but even the most inexpensive and basic system can save lives by immediately sounding an alarm if a fisherman falls overboard. Some of these systems can also benefit fishermen who work alone on small vessels by shutting down the engine if the sole operator falls overboard. This gives the fisherman, especially one prepared by wearing a PFD, a chance to get back to the vessel and re-board it.

Conduct monthly man-overboard drills - If you fell overboard, would you want it to be the first time your crewmates tried to recover a man-overboard? Practicing man-overboard recovery procedures is essential for a crew to perform well in an actual emergency.

\section{On-Board Injuries}

Install emergency stop (e-stop) devices on deck machinery - Deck machinery, especially deck winches, are particularly hazardous and result in many fatal and non-fatal injuries. Emergency-stop buttons have been developed specifically for deck machinery on fishing vessels and can be adapted and retrofitted onto any winch or other machinery. More information about e-stops for fishing vessels can be found at www.cdc.gov/niosh/topics/fishing. 


\section{National Institute for Occupational Safety and Health Alaska Pacific Regional Office}

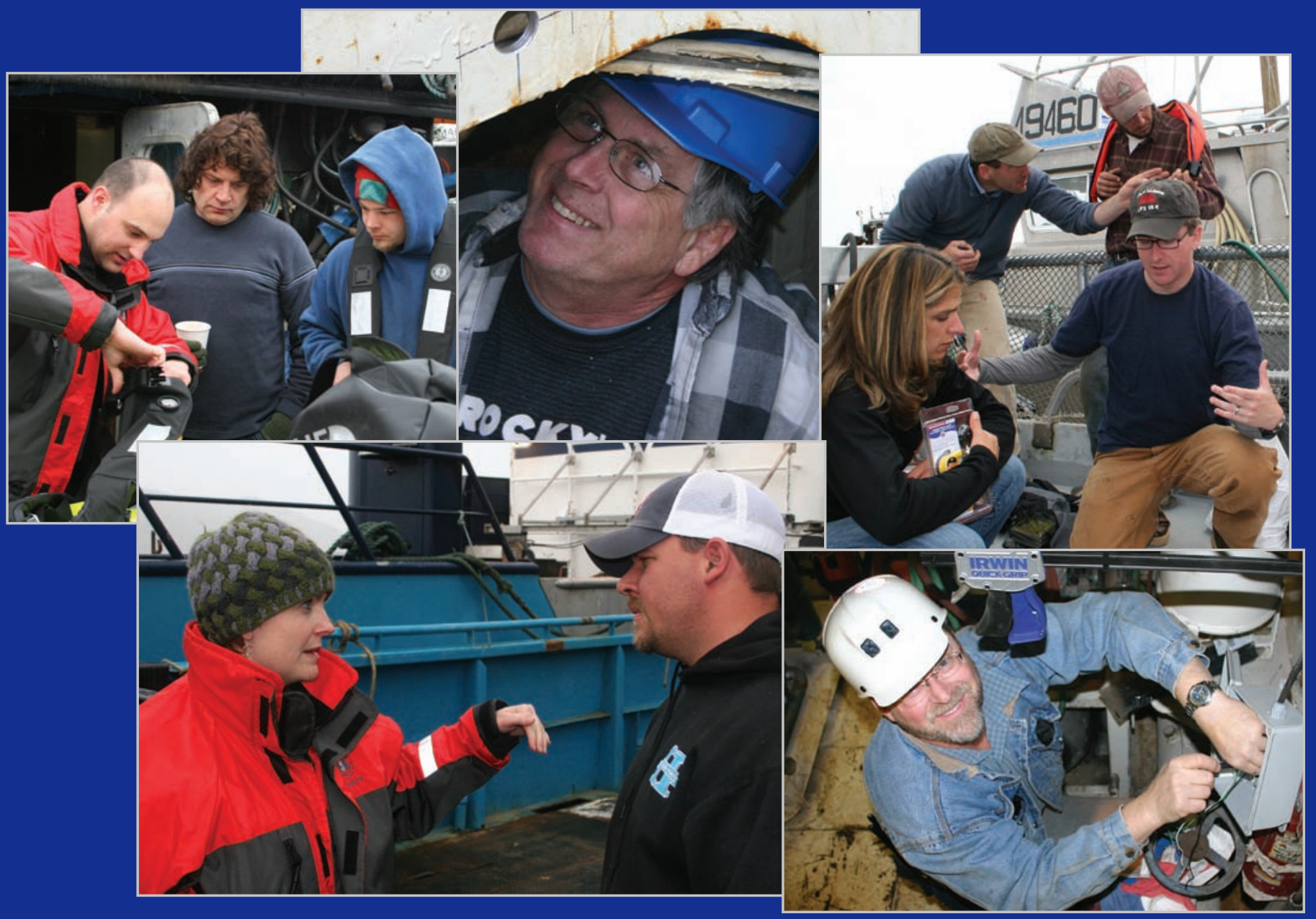

NIOSH Commercial Fishing Safety Research Program

Jennifer Lincoln and Devin Lucas

4230 University Drive, Suite 310

Anchorage, AK 99508

P: 907-271-2382

F: $907-271-2390$

cdc.gov/niosh/topics/fishing

Twitter: @NIOSHFishing

SAFER • HEALTH I ER P POPLE

Department of Health and Human Servic es

Centers for Disease Control and Prevention

National Institute for Occupational Sa fety and Health

DHHS (NIOSH) Publication Number: 2011-105

November 2010 